\section{Aspectos éticos de la epidemia del Coronavirus}

\section{Ethical issues related to Coronavirus epidemic}

\section{Señor Editor:}

La reciente epidemia de Coronavirus, reportada por China en diciembre del 2019, ha generado comprensible preocupación en la comunidad internacional, debido a su alta mortalidad y poder de contagio ${ }^{1}$. En síntesis, este nuevo Coronavirus, designado como COVID-19, produce un cuadro semejante a una neumonía; su brote se originó en Wuhan, provincia de Hubei, extendiéndose rápidamente a diversos países y continentes. $\mathrm{Ha}$ ocasionado importantes problemas de salud pública a nivel global, especialmente debido al potencial de transmisión asintomática, lo que ha significado que viajeros regresan desde China a sus respectivos países pueden contagiar a sus connacionales aún sin presentar síntomas de la enfermedad.

Debido a la experiencia adquirida durante otras epidemias, como la del SARS en China, el Ébola en África, y el Zika en Latino América², las autoridades sanitarias tomaron drásticas medidas para poner en estricta cuarentena a la población del lugar donde se inició el brote y también para aislar el virus. Apenas tres días después de haberlo aislado, China compartió el genoma viral con la comunidad internacional, lo que ha permitido una búsqueda acelerada de nuevos tratamientos y vacunas.

En este contexto, es conveniente discutir brevemente algunos temas éticos implicados en la forma de hacerle frente a esta epidemia.

En primer lugar, están los relacionados con las restricciones a las libertades individuales, puesto que las autoridades sanitarias, tanto de China como de aquellos lugares en los cuales se han detectado contagios, han impuesto un férreo control sanitario, incluyendo exámenes de salud obligatorios para personas sintomáticas expuestas al riesgo ${ }^{1}$. Un caso emblemático es la cuarentena de más de 5.000 pasajeros de dos cruceros, que no pueden salir de sus habitaciones, luego de detectarse casos positivos para el virus. Al respecto, los límites a la autonomía de las personas, incluyendo la obligatoriedad de controles médicos a viajeros sospechosos de estar infectados, estarían plenamente justificados cuando existen riesgos para terceros, especialmente si no se dispone de un adecuado tratamiento. No obstante, estas medidas restrictivas deben ser adecuadamente armonizadas con los derechos individuales de los ciudadanos a desplazarse libremente, por lo que la declaración de un cordón sanitario, ya sea en una ciudad o en un crucero, debe hacerse sin vulnerar el derecho a la privacidad y a la dignidad inherente a todo ser humano. Algunos requisitos para justificar éticamente la cuarentena se relacionan con su eficacia para controlar la propagación de la infección, si es proporcional a la severidad del cuadro, y si es necesaria para controlar la epidemia, en ausencia de otras medidas menos restrictivas ${ }^{2}$.

Un segundo aspecto se refiere a la necesaria transparencia que debe existir para reportar los nuevos casos, incluyendo datos de mortalidad, puesto que es la única manera que tienen los ciudadanos de protegerse y también permite que los equipos sanitarios tomen las medidas adecuadas para enfrentar la epidemia. Durante los inicios de la epidemia hubo períodos en los cuales se ocultaron nuevos casos en Wuhan e incluso se informó que la infección era más bien leve y tratable (para más información ver referencia 2) y se pretendió ocultar el fallecimiento del primer médico que alertó de este nuevo brote. Una medida adicional que hay que destacar es la decisión de las principales revistas de poner a disposición pública y de manera gratuita todos los trabajos relacionados con estas epidemias de alcance global, como se hizo para el Ébola ${ }^{3}$ y ahora para este nuevo virus ${ }^{4}$.

Otro tema ético se refiere al deber moral de los trabajadores sanitarios de tratar a los potenciales sujetos infectados, aún a riesgo de su propia salud y de aquellos con quienes viven. De los 17.000 casos de Ebola en Guinea, Liberia y Sierra Leona, al menos 600 correspondían a trabajadores de la salud y la mitad de ellos fallecieron ${ }^{5}$; ya hay al menos un profesional sanitario fallecido por este virus. Lo que prima acá es el deber ético del no abandono y poner siempre el interés del paciente por sobre el interés personal.

Finalmente, es necesario comentar brevemente los aspectos relacionados con la investigación en situación de emergencia sanitaria. Existen temas éticos relacionados con el consentimiento informado, incluyendo la necesidad de reclutar a sujetos que por la gravedad del cuadro, no pueden consentir; temas relacionados con la priorización del acceso a los fármacos de prueba, sobretodo si están aún etapa experimental; otros temas relacionados con los derechos y deberes de los participantes en el estudio, especialmente respecto a la responsabilidad que tienen en entregar muestras, aún cuando se hayan retirado del ensayo; también aquellos deberes de los patrocinadores del estudio respecto de los sujetos que participan en el ensayo y respecto de la comunidad donde se realiza el estudio; y por último, la necesidad de capacitar a los miembros de los Comités Ético Científicos para que puedan aprobar en tiempos cortos estos estudios, sin disminuir los estándares éticos.

$\mathrm{Al}$ respecto, las Pautas Éticas Internacionales para la Investigación Relacionada con la Salud con Seres Humanos (más conocidas como Pautas CIOMS), en su Pauta 20, han considerado requisitos éticos específicos para la investigación en estas situaciones ${ }^{6}$. Destacamos los más relevantes: 
- La investigación responde a las necesidades de salud de las comunidades afectadas, y no puede ser realizada fuera de la situación de desastre.

- Existe una justa selección de los participantes y se distribuyen de manera equitativa las posibles cargas y potenciales beneficios de la investigación.

- Existe participación activa de las comunidades involucradas en la fase de planificación del estudio, de tal modo que este tenga pertinencia cultural.

- Se obtiene un consentimiento informado de cada participante, a menos que se cumplan las condiciones para dispensa del mismo.

- Los resultados de la investigación se diseminan, se comparten los datos y se ponen a disposición de las comunidades afectadas el conocimiento que se ha generado.

Creemos que es conveniente reflexionar sobre estos aspectos, puesto que en un mundo globalizado, cualquier país puede ser afectado por estas u otras epidemias.

Sofía P. Salas ${ }^{1}$

${ }^{1}$ Centro de Bioética, Facultad de Medicina. Clínica Alemana Universidad del Desarrollo. Santiago, Chile.

\section{Referencias}

1. Phelan AL, Katz R, Gostin LO. The Novel Coronavirus Originating in Wuhan, China: Challenges for Global Health Governance. JAMA Publicado en línea el 30 enero 2020 doi:101001/jama20201097 2020.

2. Lei R, Qiu R. Report from China: Ethical questions on the response to the Coronavirus. Hastings Bioethics Forum. Disponible en https://http://www.thehastingscenter.org/report-from-china-ethical-questions-on-the-response-to-thecoronavirus/. Fecha de acceso 6 febrero 2020. 2020.

3. The Lancet Ebola Resource Centre. Disponible en https:// http://www.thelancet.com/campaigns/ebola. Fecha de acceso 6 de febrero 2020.

4. Calling all coronavirus researchers: keep sharing, stay open. Nature 578, 7 (2020). doi: 10.1038/d41586-020-00307-x. Fecha de acceso 4 febrero 2020.

5. Green A. Remembering health workers who died from Ebola in 2014. Lancet 2014; 384(9961):2201-6.

6. International ethical guidelines for health-related research involving humans. Geneva, Switzerland: Council for International Organizations of Medical Sciences (CIOMS), 2016. 